\title{
SCALING UP INTERVENTIONS FOR BETTER ACCESS TO MENTAL HEALTH AND EPILEPSY CARE - IMPACT FORUM, VERSAILLES, FRANCE, $12^{\mathrm{TH}}-14^{\mathrm{TH}}$ SEPTEMBER 2018
}

Scaling up may be defined as "deliberate efforts to increase the impact of successfully tested health innovations so as to benefit more people and to foster policy and programme development on a lasting basis".

Innovation, as used in this definition, is a set of interventions that is new or perceived as new.

There is no need to stress the importance of studying and disseminating scaling up techniques from an ethical point of view. It may be said that no innovation is really useful until it becomes standard practice and is accepted as common knowledge or guideline.

This meeting, stemming from the association between Global Health Programs at Sanofi, the World Association of Social Psychiatry (WASP) and the Institute of Epidemiology and Tropical Neurology at Limoges, France, provided an opportunity for examining the theoretical background, practical application, and selected results of scaling up in the field of mental health.

Under the organization of Dr. Pierre-Emile Bruand and his Sanofi team, the meeting provided an opportunity to examine different efforts to introduce and adopt innovations in practices, technologies, and interventions. Both the President and Secretary-General of the WASP, along with the Director of the Institute of Epidemiology and Tropical Neurology at Limoges addressed the audience.

Participants had the opportunity to evaluate the contributions made by selected documents from WHO, as studied and applied by members of a widespread research network including researchers in Armenia, Madagascar, Bolivia, Laos, and Guatemala, among other countries.

The agenda of future meetings should include a consideration of the ethical underpinnings of interventions and their scaling up.

Fernando Lolas Stepke 